\title{
Antimicrobial susceptibility of Neisseria gonorrhoeae isolated in Durban, South Africa
}

\author{
Y M COOVADIA, AYESHA KHARSANY, AND UGENDRI RAMSAROOP \\ From the Department of Microbiology, Faculty of Medicine, University of Natal, Durban, South Africa
}

SUMMARY One hundred and forty clinical isolates of Neisseria gonorrhoeae were screened for production of penicillinase by the intralactam strip method and chromogenic cephalosporin test. Minimum inhibitory concentrations (MICs) of penicillin, ampicillin, tetracycline, cefoxitin, cefuroxime, cefotaxime, sulphamethoxazole-trimethoprim (ratio 19/1), and spectinomycin, were measured for 100 strains by the agar dilution method. Seven $(5 \%)$ of the 140 isolates were identified as penicillinase producing $N$ gonorrhoeae (PPNG). The MICs of penicillin for the seven PPNG strains ranged from $0.25 \mathrm{mg} / \mathrm{l}$ to $2 \mathrm{mg} / \mathrm{l}$. Of the 93 non-PPNG strains, $80(86 \%)$ were fully susceptible to penicillin with MICs ranging from $0.0037 \mathrm{mg} / 1$ to $0.06 \mathrm{mg} / \mathrm{l}$ and $13(14 \%)$ were of intermediate penicillin resistance with MICs $\geqslant 0.125 \mathrm{mg} / \mathrm{l}$. Of the 100 isolates tested, $86 \%$ were fully susceptible to tetracycline with MICs of $<1 \mathrm{mg} / \mathrm{l}$. No spectinomycin resistant strains were encountered in this study. All gonococcal strains were susceptible to the cephalosporins tested as well as to sulphamethoxazole-trimethoprim.

\section{Introduction}

Penicillinase producing strains of Neisseria gonorrhoeae (PPNG) were first detected in South Africa in 1977 when isolated cases from Johannesburg and Durban were described. ${ }^{2}$ Since then no further isolates have been reported from this country. The microbiology laboratory at King Edward VIII Hospital, Durban, recently isolated a PPNG strain of $N$ gonorrhoeae from a black male patient who presented with gonococcal urethritis that did not respond to adequate penicillin treatment. This prompted us to conduct a study on the susceptibility of local gonococcal isolates to nine antimicrobial agents including penicillin, spectinomycin, and the newer cephalosporins.

Patients, materials, and methods

BACTERIAL STRAINS

All strains of $N$ gonorrhoeae were isolated from black male patients attending a clinic for sexually transmitted diseases (STD) at King Edward VIII Hospital, Durban. The identity of $N$ gonorrhoeae was confirmed by colony morphology, positive

Address for reprints: Dr Y M Coovadia, Department of Microbiology, University of Natal, P O Box 17039, Congella 4013, Durban, South Africa

Accepted for publication 21 February 1984 oxidase test, and direct fluorescence antibody test (Difco). The 140 gonococcal isolates so obtained were screened for penicillinase production by the intralactam strip method (Mast Laboratories) and by the chromogenic cephalosporin test. ${ }^{3}$ Isolates were stored at $-70^{\circ} \mathrm{C}$ in tryptic soy broth containing $20 \%$ $(\mathrm{v} / \mathrm{v})$ glycerol until required. Forty isolates were lost on subculture. As a result only 100 gonococcal isolates including seven PPNG strains were eventually tested.

\section{ANTIBIOTICS}

Benzylpenicillin and cefuroxime (Glaxo Laboratories), ampicillin (Beecham Laboratories), tetracycline and spectinomycin (Upjohn), cefoxitin (Merck Sharp \& Dohme), cefotaxime (Roussel Laboratories), and sulphamethoxazole and trimethoprim (Wellcome Laboratories) were all provided by their manufacturers as powders of stated potency.

\section{SUSCEPTIBILITY TESTING}

Minimum inhibitory concentrations (MICs) were determined by the agar dilution method using diagnostic sensitivity test agar supplemented with $6 \%$ lysed horse blood. A few colonies from an overnight chocolate agar plate culture were suspended into tryptic soy broth until the turbidity matched that of a $0.5 \mathrm{McF}$ arland standard. The suspension was further diluted $1 / 20$ in the same broth and $0.001 \mathrm{ml}$ of this broth was inoculated on to the test plates by means 
TABLE I In vitro susceptibility of seven PPNG isolates to eight antimicrobial agents

\begin{tabular}{|c|c|c|c|c|c|c|c|c|c|c|c|c|c|}
\hline \multirow[b]{2}{*}{$\begin{array}{l}\text { Antimicrobial } \\
\text { agent }\end{array}$} & \multicolumn{13}{|c|}{ No of isolates with MICs $(\mathrm{mg} / \mathrm{l})$ of: } \\
\hline & 0.0037 & 0.0075 & 0.015 & 0.03 & 0.06 & $0 \cdot 125$ & 0.25 & 0.5 & $I$ & 2 & 4 & 8 & 16 \\
\hline \multirow{7}{*}{$\begin{array}{l}\text { Penicillin G } \\
\text { Ampicillin } \\
\text { Tetracycline } \\
\text { Cefuroxime } \\
\text { Cefoxitin } \\
\text { Cefotaxime } \\
\text { Spectinomycin } \\
\text { Sulphamethoxazole- } \\
\text { trimethoprim }\end{array}$} & & & & & & & 1 & & & 6 & & & \\
\hline & & & & & & & & & 3 & 3 & 1 & & \\
\hline & & 7 & & & & 1 & & 4 & 2 & & & & \\
\hline & & & & & & 6 & 1 & & & & & & \\
\hline & 6 & 1 & & & & & & & & & & 5 & 2 \\
\hline & & & & & & & & & & & & J & 2 \\
\hline & & & & & & & & & & & 3 & 3 & 1 \\
\hline
\end{tabular}

*19/1 ratio

of a multipoint inoculator (Denleys Instruments). The final inoculum size was about $10^{4}-10^{5}$ colony forming units (cfu). The Oxford Staphylococcus aureus was included as a control. In addition plates containing no antibiotics were inoculated before and after each run. Plates were read after overnight incubation in a candle extinction jar, and the MIC was the lowest concentration of antibiotic that completely inhibited growth of the organism.

\section{Results}

Seven $(5 \%)$ of the 140 gonococcal isolates were positive for penicillinase ( $\beta$-lactamase) production by the intralactam strip method and chromogenic cephalosporin test. Table I shows the MICs for the seven PPNG strains; MICs of penicillin were $2 \mathrm{mg} / \mathrm{l}$ for six strains and $0.25 \mathrm{mg} / \mathrm{l}$ for one, and the MIC of ampicillin was $>0.5 \mathrm{mg} / \mathrm{l}$ for all seven strains. The isolates were fully susceptible to spectinomycin and the cephalosporins. Cefoxitin with a MIC of $0.25 \mathrm{mg} / \mathrm{l}$ was the least effective of the three cephalosporins tested. The MICs of sulphamethoxozole-trimethoprim ranged from $4 \mathrm{mg} / \mathrm{l}$ to $16 \mathrm{mg} / \mathrm{l}$, and MICs of tetracycline were $\leqslant 1 \mathrm{mg} / \mathrm{l}$ for all seven isolates.

Table II shows the MICs for the 93 non-PPNG strains. None of the isolates in this group had MICs of penicillin or ampicillin of $>0.5 \mathrm{mg} / \mathrm{l}$. Penicillin, however, (median MIC $<0.004 \mathrm{mg} / \mathrm{l}$ ) was generally more active than ampicillin (median MIC 0.0225 $\mathrm{mg} / \mathrm{l})$. Tetracycline inhibited $81(87 \%)$ of the isolates at concentrations $<1 \mathrm{mg} / \mathrm{l}$. All the isolates were fully susceptible to spectinomycin and sulphamethoxazoletrimethoprim, which had MICs of $\leqslant 32 \mathrm{mg} / 1$ and $\leqslant 16$ $\mathrm{mg} / \mathrm{l}$ respectively. Using as the criterion the MIC at which $50 \%$ of isolates were inhibited, the order of activity among the cephalosporins was: cefotaxime (MIC $50=<0.004 \mathrm{mg} / \mathrm{l})$, cefuroxime (MIC $50=$ $0.006 \mathrm{mg} / \mathrm{l}$ ), and cefoxitin (MIC $50=0.086 \mathrm{mg} / \mathrm{l}$ ).

The figure compares the activity of penicillin, ampicillin, and the cephalosporins against the seven PPNG and 93 non-PPNG strains. Although penicillin was generally more active than ampicillin, the order of activity was reversed against the non-PPNG strains that had MICs of penicillin $>0.06 \mathrm{mg} / \mathrm{l}$. The difference between the MICs of the cephalosporins for the PPNG and non-PPNG strains was minimal, in contrast to the difference between the penicillins. Although cefotaxime and cefuroxime were as active as the penicillins against non-PPNG strains, both these cephalosporins were far more active against PPNG strains. Cefotaxime was the most active of the cephalosporins against all strains of $N$ gonorrhoeae.

TABLE II In vitro susceptibility of 93 non-PPNG isolates to eight antimicrobial agents

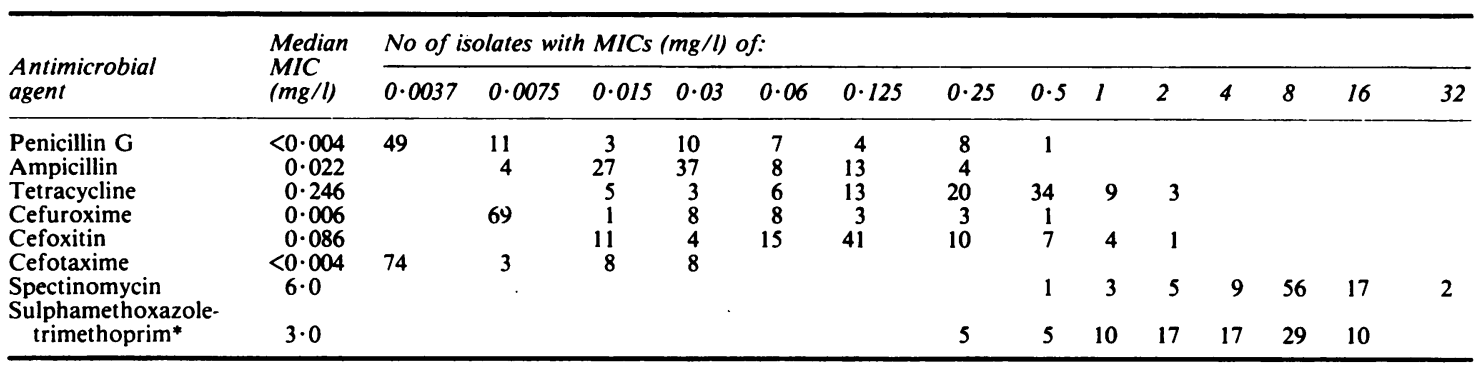

* $19 / 1$ ratio 


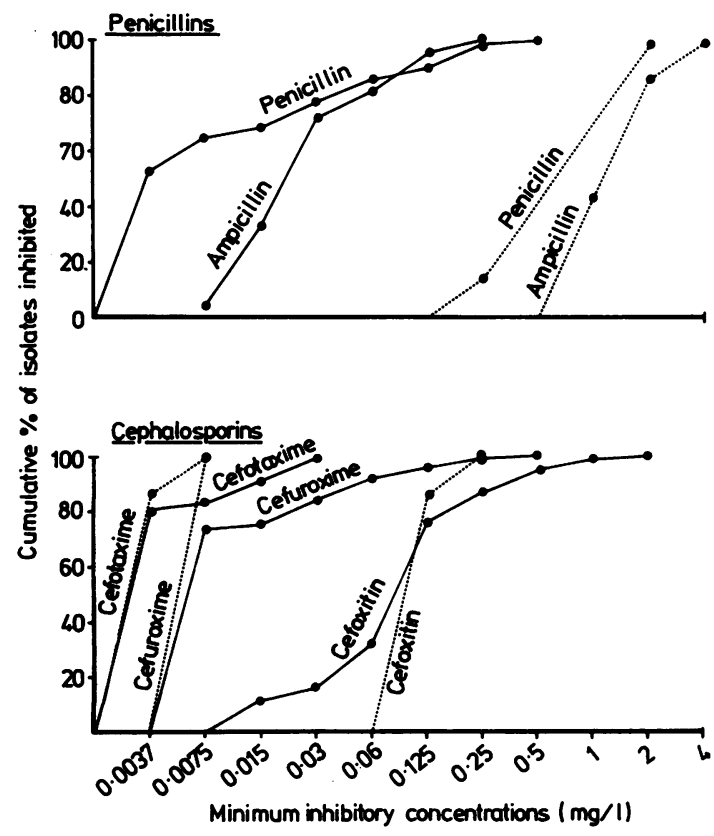

FIGURE Comparison of penicillin $G$, ampicillin, cefuroxime, cefoxitin, and cefotaxime antimicrobial activity against 93 non-PPNG $(\bullet-)$ ) and seven PPNG

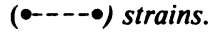

\section{Discussion}

PPNG strains have been found in West Africa, ${ }^{4}$ Zambia, ${ }^{5}$ and Zimbabwe, ${ }^{6}$ but the extent of the problem in most African countries is not yet known. Since the original two reports on the isolation of PPNG in South Africa in 1977, 12 no further cases have been documented. In this study we detected penicillinase ( $\beta$-lactamase) production in seven $(5 \%)$ of $\mathbf{1 4 0}$ gonococci isolated from black male patients who presented with urethral discharge at an STD clinic in Durban. Since the completion of this study, an additional 15 PPNG strains have been isolated. These findings confirm that PPNG is now present in the indigenous black population of Durban.

Of the 93 non-PPNG strains, $13(14 \%)$ showed intermediate resistance to penicillin with MICs of $\geqslant 0.125 \mathrm{mg} / \mathrm{l}$. This percentage is appreciably lower than those reported recently from $\mathrm{Zambia}^{5}$ and Hong Kong. ${ }^{7}$ As reported by others, ${ }^{89}$ we also found that ampicillin was more effective than penicillin against strains of $N$ gonorrhoeae showing intermediate resistance to penicillin (MICs $0 \cdot 125 \mathrm{mg} / \mathrm{l}-0.5 \mathrm{mg} / \mathrm{l}$ ). In contrast to the findings of $\mathrm{Ng}$ et $a l,{ }^{7} 87 \%$ of our non-PPNG strains were fully susceptible to tetracycline with MICs of $<1 \mathrm{mg} / \mathrm{l}$, which is comparable with those reported in a recent study from Johannesburg. ${ }^{8}$

All the isolates, including the seven PPNG strains, were susceptible to spectinomycin, sulphamethoxazole-trimethoprim, and the cephalosporins. Cefotaxime was the most active of the three cephalosporins against both PPNG and non-PPNG strains; all isolates were inhibited by concentrations of $\leqslant 0.03$ $\mathrm{mg} / \mathrm{l}$. These results confirm those reported by others. ${ }^{78}$ Cefuroxime and cefotaxime were found to be as active as penicillin against non-PPNG strains but were far more active than both penicillin and ampicillin against PPNG strains. These cephalosporins may prove useful alternatives to spectinomycin for the treatment of infections caused by $N$ gonorrhoeae resistant to penicillin. The seven PPNG strains had MICs of tetracycline $\leqslant 1 \mathrm{mg} / \mathrm{l}$, which confirms published reports that PPNG strains in West Africa are still relatively susceptible to tetracycline. ${ }^{10}$

Most gonococcal isolates tested, therefore, remain susceptible to penicillin and the other antimicrobials tested. Further studies are required, however, to determine the real extent of the problem of $N$ gonorrhoeae resistant to penicillin in Durban and in the rest of South Africa.

We thank the staff of the STD clinic, King Edward VIII Hospital for their cooperation and help. We also thank Dr M Richter, the Medical Officer of Health, Durban, for granting us permission to undertake the study and for allowing us to publish the findings.

\section{References}

1. Robins-Browne RM, Gaillard MC, Koornhof HJ. Penicillinaseproducing Neisseria gonorrhoeae. S Afr Med J 1977;51:568.

2. Hallet AF, Appelbaum PC, Cooper R, Mokgokong S, MonaleD Penicillinase-producing Neisseria gonorrhoeae from South Africa. Lancet 1977 ; i: 1205.

3. O'Callagham $\mathbf{C H}$, Morris A, Kirby SM, Shingler AH. Novel method for detection of $\beta$-lactamase by using a chromogenic cephalosporin substrate. Antimicrob Agents Chemother 1972; 1:283-8.

4. Osoba AO. Sexually transmitted diseases in tropical Africa: a review of the present situation. Br J Vener Dis 1981:57:89-94.

5. Ratnam AV, Patel MI, Mulenga RC, Hira SK. Penicillinaseproducing gonococcal strains in Zambia: observations on treatment failures. $\mathrm{Br} J$ Vener Dis 1982;58:29-31.

6. Latif AS. Sexually transmitted diseases in Harare, Zimbabwe. Southern African Journal of Sexually Transmitted Diseases 1982; 2:21-3.

7. $\mathrm{Ng}$ WS, Anton $\mathrm{P}$, Arnold K. Neisseria gonorrhoeae strain isolated in. Hong Kong: in vitro susceptibility to 13 antibiotics. Antimicrob Agents Chemother 1981;19:12-7.

8. Liebowitz LD, Ballard RC, Koornhof $\mathrm{HJ}$. In vitro susceptibility and cross-resistance of South African isolates of Neisseria gonorrhoeae to 14 antimicrobial agents. Antimicrob Agents Chemother 1982; 22:598-603.

9. Thornsberry $\mathrm{C}$, Baker $\mathrm{CN}$, Jones RN. In vitro antimicrobial activity of piperacillin and seven other $\beta$-lactam antibiotics against Neisseria gonorrhoeae and Haemophilus influenzae, including $\beta$-lactamase producing strains. $J$ Antimicrob Chemother 1979;5: 137-42.

10. Perine PL, Schalla W, Siegel MS, Thornsberry C, Biddle J, Wong KH. Evidence for two distinct types of penicillinaseproducing Neisseria gonorrhoeae. Lancet 1977; ii:993-5. 